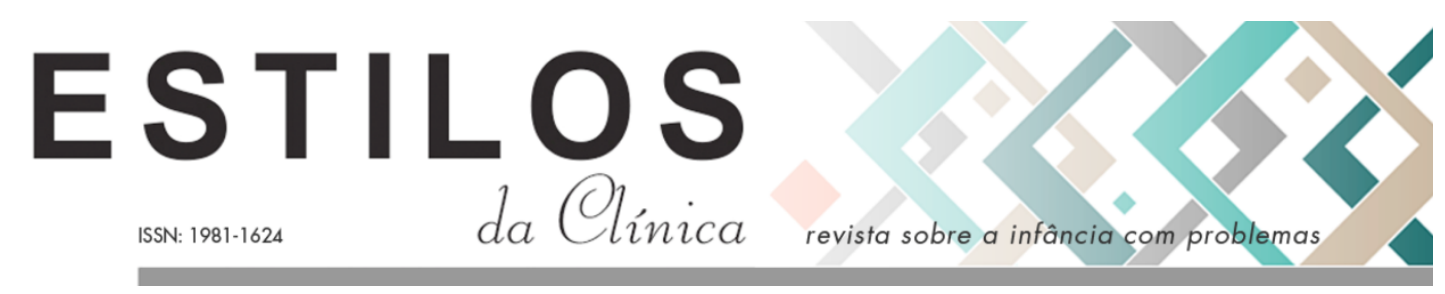

DOI: https://doi.org/10.11606/issn.1981-1624.v24i1p98-110.

\title{
Artigos \\ O paradoxo da unidade na dualidade: elementos para a clínica dos casos-limite*
}

\author{
Cristiana de Aguiar Pondé1; Carlos Augusto Peixoto Jr. ${ }^{2}$
}

Resumo. O artigo irá aprofundar o debate acerca dos primórdios da constituição psíquica e sua relação com a etiologia dos casos-limite. Assim, apesar de não se tratar de um artigo sobre a infância, eixo principal desta revista, ele aporta a uma discussão teórica sobre a constituição psíquica e sobre a importância das interações iniciais da vida na etiologia dos casos-limite. Em seu primeiro eixo, discutiremos os primórdios do psiquismo como fonte de subsídios para uma clínica dos casos-limite, já que estes casos são compreendidos como marcados por traumas no âmbito das primeiras relações de objeto. Observa-se, na relação transferencial com estes pacientes, mecanismos de defesa verticais, como cisões, mais frequentemente do que mecanismos de defesa horizontais, como o recalque. O recalque foi o conceito central para a constituição da técnica psicanalítica clássica. Este fato faz com que nos defrontemos com a necessidade de refinamento da técnica analítica para abordar de forma mais eficaz estes casos que desafiam a técnica clássica. Neste sentido, estudaremos, no segundo eixo deste trabalho, a contratransferência sob uma perspectiva da intersubjetividade e da valorização da qualidade da relação analítica.

Palavras-chave: teoria das relações de objeto; trauma precoce; estados esquizoides; casos-limite; identificação projetiva.

\section{La paradoja de la unidad en la dualidad: elementos para la clínica de los casos límite}

Resumen. El artículo busca profundizar en el debate acerca de los principios de la constitución psíquica y su relación con la etiología de los casos dudosos. Aunque su tema no es sobre la infancia, línea principal de esta revista, plantea una discusión teórica sobre la constitución psíquica y la importancia de los primeros años de vida en la etiología de los casos límite. En su primer eje central, se exponen los principios del psiquismo como una

\footnotetext{
* Agradecimentos ao Programa de Pós-graduação em Psicologia Clínica da Pontifícia Universidade Católica do Rio de Janeiro (PUC-Rio), à agência de fomento Capes e aos meus pares nesta jornada que é a formação permanente em Psicanálise.

1. Psicanalista, doutoranda do Programa de Pós-Graduação em Psicologia Clínica da Pontifícia Universidade Católica do Rio de Janeiro (PUC-Rio), Rio de Janeiro, RJ, Brasil, com período de doutorado sanduíche na Universidade do Porto, Portugal. E-mail: cristianaponde@gmail.com

2. Psicanalista, professor do Departamento de Psicologia e do Programa de Pós-Graduação em Psicologia Clínica da Pontifícia Universidade Católica do Rio de Janeiro (PUC-Rio), Rio de Janeiro, RJ, Brasil. E-mail: cpeixotojr@terra.com.br
} 
fuente de subvenciones para una clínica de casos límite, puesto que estos son marcados por traumas en el contexto de las primeras relaciones de objeto. Se observa en la relación de transferencia con estos pacientes los mecanismos de defensa vertical como divisiones más frecuentes que mecanismos de defensa horizontal, como la represión. La represión fue el concepto central para el establecimiento de la técnica psicoanalítica clásica. Este hecho nos hace abordar la necesidad de refinamiento de la técnica analítica para exponer más eficazmente estos casos que desafían a la técnica clásica. En este sentido, en el segundo eje de este trabajo, vamos a estudiar la contratransferencia bajo una perspectiva de la intersubjetividad y la apreciación de la calidad de la relación analítica.

Palabras clave: teoría de las relaciones de objeto; trauma temprano; personas en estados esquizoides; casos límite; identificación proyectiva.

\section{The paradox of unity in duality: elements for the clinic of borderline cases}

Abstract. The article will deepen the debate about the beginnings of psychic constitution and its relation to the etiology of borderline cases. So, although this is not an article about childhood, main axe of this journal, it brings a theoretical discussion about the psychic constitution and the importance of the early interactions of life in the etiology of borderline cases. In the first axe, early objects relationships and the reorganization of the initials attachments as a source of subsidies for a clinic of borderline cases will be discussed. These cases are understood as marked by early trauma in the context of the first object relationships. It is noted, in relation to transference with these patients, vertical defense mechanisms, such as splitting, emerge more frequently than horizontal defense mechanisms, such as repression. The repression was the central concept for the establishment of classical psychoanalytic technique. This fact makes us tackle the need for refinement of analytical technique for approaching more effectively these cases that challenge the classical technique. In this sense, we will study, in the second axis of this paper, the countertransference under a intersubjectivity perspective and the appreciation of the quality of the analytical relationship.

Keywords: object relations theory, early trauma, persons with schizoid states, borderline cases, projective identification.

$\mathrm{N}_{\mathrm{a}}$ clínica psicanalítica contemporânea, cada vez mais se escutam sujeitos que "sofrem" de sentimentos de vazio e de futilidade, cujo trabalho psíquico parece estar voltado para questões relativas às possibilidades de existência psíquica. Sujeitos que estão ocupados primordialmente com a sobrevivência e com a necessidade de manterem-se coesos. São os chamados casos-limite, onde a intensidade e a frequência de processos projetivos e das cisões de partes do self determinarão a especificidade da relação analítica que irão estabelecer. Nestes casos, as experiências serão predominantemente atuadas na transferência em busca de uma possível elaboração simbólica.

As experiências sensoriais discutidas por D. Winnicott (1960/1983, 1963/1983, 1951/2000), E. Bick (1967/1991) e F. Tustin (1990) ocupam a cena principal na vida psíquica e nas relações de objeto estabelecidas pelos sujeitos que chegam aos consultórios, nomeadamente, os casos-limite. Ao invés de serem sublimadas e transformadas pelos processos simbólicos, como nas áreas mais maduras da personalidade, desencadeiam processos sucessivos de cisões e projeções, com o consequente enfraquecimento do ego e das relações com os objetos. Trata-se de experiências anteriores a qualquer possibilidade de dor ou de prazer.

Segundo Figueiredo (1999), a problemática esquizoide que compõe a psicodinâmica destes casos, refere-se a uma contração do eu para dentro do mundo interno a partir das experiências de frustração nas relações objetais, em momentos anteriores ao predomínio do princípio do 
prazer como princípio regente dos processos psíquicos. A partir deste enfoque, abordaremos o tema da fragilidade das fronteiras do eu, conduzindo a fenômenos de "derramamento" deste eu sobre o mundo externo, alternando-se às contrações do eu para dentro de seu mundo interno.

Falhas na função continente do ambiente cuidador ou uma excessiva intolerância a frustrações por parte do bebê (Bion, 1963/1994) acarretam um transbordamento das angústias primitivas para outras áreas do psiquismo e excessivas projeções nos objetos externo. Estas cisões e projeções excessivas, ao mesmo tempo em que buscam nas relações de objeto novas experiências que possam finalmente oferecer um continente adequado e uma transformação em símbolos, danificam as relações com estes objetos internos e externos. Tendo em vista a gravidade do sofrimento psíquico engendrado por intensas "falhas básicas" (Balint, 1968/1993) que se estendem por toda a estrutura psicobiológica do sujeito, originando patologias psicossomáticas, narcísicas, adições etc. considera-se fundamental um aprofundamento das pesquisas sobre os primórdios da constituição psíquica e sua relação com a etiologia dos casos-limite. Assim, pode-se compreender melhor não só pacientes mais intensamente regredidos como também os aspectos mais primitivos de pacientes neuróticos.

\section{Primórdios de constituição do self: o paradoxo da unidade na dualidade}

A experiência da unidade na dualidade refere-se ao contexto da relação de objeto, em que estão se constituindo as fundações para uma experiência de separação eu e outro, mundo interno e mundo externo. Esta ideia de uma "unidade relacional", desenvolvida por Anne Alvarez (1994), origina-se tanto da concepção de Winnicott (1963/1983) que se refere à matriz mãe-bebê como uma nova entidade psicológica, como também da concepção kleiniana (1946/1991) da posição esquizoparanoide. Esta posição é caracterizada por formas primitivas de relação de objeto onde as fronteiras entre ego e objeto, entre mundo interno e externo ainda não estão muito bem delimitadas. Visando investigar os processos primordiais de constituição subjetiva, percorreremos algumas contribuições de M. Klein (1946/1991a, 1952/1991b), F. Tustin (1990) e Esther Bick (1967/1991) sobre a constituição destas fronteiras psíquicas entre o eu e o outro, experiências fundamentais para a emergência do self.

A teoria das posições de Klein refere-se às duas diferentes dimensões da experiência em que as relações objetais estão inseridas. Postula dois grupos específicos de ansiedades, defesas, formação de símbolos e relações de objeto que correspondem a uma dupla dimensão da vida mental: a posição esquizoparanoide e a posição depressiva. A posição esquizoparanoide, constituída por aspectos mais primitivos, refere-se a uma organização psíquica movida pelo ego incipiente para lidar com as ansiedades e fantasias geradas pelos embates entre a pulsão de morte e a pulsão de vida na relação com os primeiros objetos. Nos momentos em que predomina a pulsão de morte, o objeto externo é vivido pelo bebê, a partir de suas projeções, como objeto hostil. O bebê odeia e teme o objeto mau; assim desenvolvese uma situação persecutória, protótipo de toda relação de objeto hostil. Paralelamente, fontes primitivas de amor fundadas pela pulsão de vida são projetadas, criando o objeto bom como protótipo das relações de objeto amorosas. Devido à incapacidade do ego incipiente para experienciar a ambivalência, estas duas qualidades opostas atribuídas ao objeto primordial devem ser mantidas tão separadas quanto possível, o que se realiza através de uma cisão no objeto. 
Klein (1952/1991b citado por Steiner, 1992/1994) concebe uma crescente capacidade de síntese e integração do ego devido a um impulsionamento da libido na direção de novos objetos, ao desenvolvimento de habilidades físicas e mentais e à adaptação progressiva ao mundo externo. A partir do relativo êxito na posição esquizoparanoide, o ego vai ganhando força com a introjeção das experiências com o objeto bom, encaminha-se na direção de uma relação com objetos totais, torna-se potente para lidar com experiências de amor e ódio dirigidas ao mesmo objeto, necessitando menos dos processos de cisão. Estas experiências de ambivalência são consideradas mais sofisticadas para o psiquismo pois incluem vivências de culpa e reparação. Ou seja, no âmbito da experiência de ambivalência, o ego é convocado a lidar com a impossibilidade de proteger o objeto de seus próprios impulsos hostis e se haver com os limites de sua capacidade de reparação, o que implica em uma maior tolerância e adaptação ao princípio de realidade. Assim, torna-se possível o trânsito para a posição depressiva e o surgimento das ansiedades depressivas. Nesta dimensão da experiência relacional, o self e o objeto, o mundo interno e o mundo externo podem estar mais firmemente delimitados.

Alguns conceitos winnicottianos fundamentam a ideia de uma unidade relacional formada por mãe e bebê e dando origem a uma nova entidade: o composto mãe-bebê. Winnicott (1951/2000) afirma que "não existe algo como o bebê, como uma entidade separada da mãe" (p. 40). O conceito de uma preocupação materna primária concebe a contribuição da mãe neste composto mãe-bebê, pois representa um aspecto desta que, por estar confundida por identificação com seu bebê, torna-se capaz de estabelecer uma comunicação em um nível sensorial com ele. A partir deste estado de unidade com o bebê, a mãe torna-se apta também a receber as projeções deste bebê e, assim, contê-las, oferecendo formas simbólicas e pensáveis para os estados primitivos de angústias sem nome vividos pelo bebê. A contribuição do bebê para este estado de unicidade indivisível é representada pelo uso que Winnicott faz da ideia da ilusão "de criar o seio", ou seja, a experiência da ilusão de que a necessidade não existe, vivida pelo bebê no estágio de relação com um objeto subjetivo. Neste estágio, realidades interna e externas são uma coisa só, tanto quanto as entidades de eu e não-eu. Assim, Winnicott (1951/2000) concebe o cuidado materno suficientemente bom como aquele que não é percebido, por estar lá de forma discreta, permitindo ao bebê experimentar a continuidade da existência e fruir dela sem intromissões nem interrupções.

Esther Bick e Frances Tustin, a partir de suas experiências clínicas com pacientes adultos e crianças, contribuíram para a discussão sobre a constituição das fronteiras psíquicas entre o eu e o não-eu. Esther Bick (1967/1991) propõe a existência de experiências de não diferenciação entre o ego incipiente e o objeto, que antecederiam as experiências de cisão primária da posição esquizoparanoide. Este período de não diferenciação implica a pressuposição de que a personalidade não existe como um todo no início. Ou seja, de acordo com Esther Bick, a experiência é vivida pelo bebê como partes não conectadas entre si e que, portanto, devem ser mantidas unidas por algo que exerça esta função. A pele é sentida como determinando este limite. Nas palavras de Bick (1967/1991), "esta função interna de conter as partes do self depende, inicialmente, da introjeção de um objeto externo, sentido como capaz de cumprir esta função" (p. 194). Mais tarde, a identificação com esta função do objeto substitui o estado não integrado e dá origem à fantasia de espaços internos e externos.

Estas experiências, segundo Bick, se dão no contexto da amamentação, cujo objeto ótimo é o mamilo na boca, a mãe que segura a criança, fala com ela e tem um cheiro familiar. $\mathrm{O}$ conjunto destas experiências sensoriais facilitará o processo de introjeção desta função 
continente, a qual é sentida concretamente como uma pele que irá conter o ego e o objeto. Frances Tustin (1990), ao conceber áreas da personalidade denominadas "cápsulas autistas", afirma que a primeira "imagem" corporal proprioceptiva define-se por ser de natureza fluida e que o papel desempenhado por estas primeiras sensações no estabelecimento de um senso de existência é fundamental para um senso de "eu".

Tendo em vista o fato de que os bebês recém-nascidos emergem de um meio líquido e de que sua primeira alimentação e excreção estão associadas com gases e líquidos, Tustin (1990) propõe que, antes mesmo da experiência de sentir-se contido pela pele, o "eu sentido" é experimentado em termos destes gases e líquidos. Esta hipótese foi construída a partir do relato de pacientes adultos que utilizaram imagens de suas experiências posteriores de fala para comunicar sensações e estados corporais primordiais não verbais.

A psicanalista inglesa sugere que é como se o recém-nascido tivesse que fazer uma adaptação de uma criatura da água para um habitante da terra seca. No entanto, em seus estados fluidos, são dominados por terrores fantasísticos e inomináveis que podem ser equacionados ao temor de explodir ou vazar através de buracos. Nestes momentos de terror, os objetos-sensação assumem a função defensiva de bloquear os buracos através dos quais o "eu sentido" pode vazar ou irromper. No entanto, tal como na experiência de constituição da função continente da pele descrita por Esther Bick (1967/1991), as identificações com situações externas reguladoras, ou seja, com os cuidados fisiológicos e afetivos permitem a constituição da representação de um "sistema de canos". Os cuidados maternos criariam o sentido de serem capazes de controlar o fluxo de fluidos corporais e, assim, tornam-se um dos precursores de uma consciência transitória de "eu" e "não-eu".

Peixoto Jr. (2011) discute a questão dos limites da representação psíquica no contexto da experiência esquizoide. O autor (2011) utiliza o termo esquizoide para referir-se "ao aspecto de todas as personalidades que está organizado em torno do apego defensivo inconsciente do self aos objetos internos" (p. 93). Inspirado por uma visão fairbairniana e não-estrutural da personalidade, Peixoto Jr. nos lembra a questão da intensidade e frequência do uso de mecanismos de defesa esquizoides, que, apesar de constituírem uma dimensão comum da personalidade, consistem também na base para diversas patologias de caráter esquizoide e também narcísicas. Refere os sentimentos de "futilidade e vazio", tão frequentemente encontrados na clínica dos casos-limite, aos predominantes mecanismos de defesa tais como a divisão do ego e a identificação projetiva. Segundo Peixoto Jr. (2011), o uso excessivo destes mecanismos leva a um empobrecimento do ego e também da relação com objetos externos.

\section{As falhas ambientais e os processos de cisão: estados esquizoides, a área da falha básica e o falso self}

Para compreender o papel das falhas ambientais nos processos psíquicos subjacentes aos casos-limites, investigaremos três conceitos de autores pertencentes ao Grupo Independente de Psicanálise Britânica: os pacientes esquizoides (Fairbairn, 1940/1980), a categoria de falso self (Winnicott, 1960/1983) e os pacientes da área da falha básica (Balint, 1968/1993). Todos estão intimamente relacionados à concepção de casos-limite adotada neste trabalho. Para os analistas do Grupo Independente de Psicanálise, o sofrimento psíquico primordial destes indivíduos deve ser compreendido em sua dimensão traumática e referido às primeiras relações de objeto (Peixoto Junior, 2013). Trauma, neste referencial, trata-se de sucessivos 
desencontros precoces entre as necessidades psicobiológicas do bebê e o cuidado material, psicológico e afetivo disponível em momentos relevantes (Balint, 1968/1993).

Para Fairbairn (1940/1980), a gênese da subjetividade consiste na busca por relação. Este autor conceitua a libido como movimento em busca de objeto, em contrapartida à visão clássica freudiana da redução de tensão pela descarga. O autor considera que este objeto já é, desde o início, objeto da realidade factual e percebido como tal pelo bebê, consequentemente, o ambiente torna-se o protagonista no processo de constituição psíquica. Ele propõe um ego inicial capaz de lidar com o objeto da realidade factual. A partir das primeiras frustrações geradas no desencontro entre as necessidades deste ego inicial e as possibilidades do ambiente em atendê-las, inicia-se um processo de internalização destas relações com "objetos maus".

Fairbairn propõe um aparelho psíquico constituído por estruturas dinâmicas, ou seja, estruturas que são também fonte de suas próprias energias. Este ponto de vista rechaça a ideia da existência de algo como o id, reservatório de energia livremente móvel, desvinculada de qualquer estrutura, bem como exclui a ideia de uma estrutura sem energia, tal como formulada por Freud em sua concepção de ego. Fairbairn (1940/1980) considerou a posição esquizoide como a mais fundamental posição da constituição psíquica. O psicanalista escocês descreve as dinâmicas relacionais, ansiedades preponderantes e mecanismos de defesa presentes nos chamados pacientes esquizoides. Os fenômenos esquizoides são compreendidos como originando-se na fase de dependência infantil, dividida em fase oral primária e fase oral secundária. Fairbairn, ao mesmo tempo em que dialoga com a teoria das fases libidinais de Karl Abraham, não se satisfaz com esta. Diverge no ponto em que Abraham (citado por Fairbairn, 1940/1980) nomeia-as de acordo com suas zonas erógenas, pois, para Fairbairn, o principal enfoque deve ser dado ao objeto ao qual a libido se dirige. Assim, substitui a teoria das fases libidinais por três etapas no curso do desenvolvimento libidinal: a dependência infantil, a etapa de transição e a etapa da dependência madura.

A dependência infantil, segundo Fairbairn (1940/1980), caracteriza-se pela fase oral primária e pela fase oral secundária. O conflito central que se estabelece na fase oral primária diz respeito ao sugar ou não sugar o seio, entendido como amar ou não amar. $\mathrm{Na}$ fase oral secundária, o conflito se dá entre sugar ou morder o seio, entendido como amar ou odiar. Esta etapa inicial caracteriza-se por uma maior indiferenciação entre o ego e o objeto, e por um consequente processo de identificação primária derivado da dependência extrema. Assim, a ameaça de perda do objeto é vivida como ameaça de perda de parte do próprio ego. $\mathrm{E}$ a angústia central refere-se à angústia de separação. A etapa de transição caracteriza-se por ser uma etapa de conflito, mas também por ser a etapa das técnicas defensivas que surgem para lidar com as ansiedades originadas na dependência infantil. Já a etapa da dependência madura é marcada por um tipo de relação mais diferenciada entre o ego e o objeto, onde não há disparidade de dependência, nem mecanismos de incorporação ou de identificação primária.

A singularidade da experiência traumática nos primórdios da constituição psíquica tanto pode representar formas básicas de constituição subjetiva, como formas desestruturantes com consequências psicopatológicas. Fairbairn enfatiza o lugar da alteridade de forma radical, valorizando a experiência com o ambiente e sua qualidade para a emergência dos processos de subjetivação.

Balint, citado por Peixoto Jr. (2013), localizou a etiologia dos chamados "casos difíceis" em uma discrepância entre as necessidades biopsicológicas nas fases formativas do indivíduo e o cuidado material, psicológico e afetivo disponível em momentos relevantes. Desenvolveu, então, a partir da experiência clínica com pacientes muito regredidos, uma nova teoria da 
mente. Ao entrar em contato com o sofrimento destes pacientes, identificou a natureza de uma "falha", contrapondo-se à ideia de conflito ou complexo, pertencente ao nível edípico. Esta "falha" pertenceria à área da experiência bipessoal no contexto das relações de objeto precoces, por isso, chamada "básica".

Balint (1968/1993) refere-se à reação destes pacientes, caso percebam que o analista não está "ligado" a eles da forma que esperam, como um sentimento de vazio, perda, morte, associado a uma aceitação tácita de tudo o que lhe está sendo oferecido. B. Joseph (1975/1992) também relata observar um forte sentimento de vazio nos pacientes de difícil acesso. E a partir da contratransferência, observa uma situação onde tudo parece fácil demais, agradável e sem conflitos, ou, então, emergem sinais de conflito que logo se dissipam. O que significaria um sinal diagnóstico de que o trabalho analítico atingiu o nível da área da falha básica. Esta área não apresenta a estrutura de um conflito, mas sim de uma falha provocada por alguém que se descuidou e que, agora, busca uma nova oportunidade para que esta possa ser preenchida.

Winnicott (1960/1983, 1963/1983, 1951/2000) dedica-se, tal como Fairbairn (1940/1980) e Balint (1968/1993), a descrever o crescimento do ego para além de suas necessidades instintivas. Em uma linha fairbairniana, também não se opõe à teoria clássica do desenvolvimento que se inscreve a partir das zonas erógenas, no entanto, nos apresenta um processo de maturação que implica necessariamente a socialização. $\mathrm{O}$ psicanalista inglês vai centrar-se no conjunto de necessidades que compõe a jornada do ego da dependência absoluta rumo à independência. Segundo o próprio Winnicott (1963/1983), a vantagem desta abordagem é o fato de permitir uma discussão tanto sobre os aspectos pessoais quantos os aspectos ambientais envolvidos nos processos de maturação, os quais foram pensados a partir de três categorias: a dependência absoluta, a dependência relativa e o rumo à independência.

A categoria de dependência absoluta define o momento desde a concepção iniciada pelo casal parental, o habitar o interior do corpo da mãe, o estado de ser carregado em seu colo até o pertencimento ao lar familiar. Neste início, Winnicott (1963/1983) descreve um estado especial vivido por parte da mãe devotada comum, no qual ela estabelece um alto grau de identificação com seu bebê que a torna capaz de colocar-se em seu lugar e, assim, entender suas necessidades e desconfortos. Este autor nomeou este estado especial como "preocupação materna primária", a partir do qual a mãe pode realizar uma adaptação mais favorável às complexas exigências do bebê neste momento de dependência absoluta. O que proporcionará a provisão ambiental necessária para proteger o bebê dos incômodos e irritações, preservando o vir a ser deste bebê. Há uma concepção de um corpo-mente inseparável, onde as experiências de cuidados físicos darão origem às experiências de uma existência psíquica. $\mathrm{O}$ ambiente, representado pela mãe que embala o bebê em seus braços, mantém-lhe a temperatura agradável, chama-o pelo seu nome, somado às experiências instintivas que tendem a aglutinar a personalidade a partir de dentro, formará o conjunto de experiências que, gradualmente reunidas, permitirá a integração das mesmas em dois seres separados: a mãe e o bebê.

Falhas relacionadas a processos que se desenvolvem nos primeiros meses de vida estarão relacionadas a sofrimentos psíquicos graves em pacientes adultos, na perspectiva winnicottiana. Para o psicanalista inglês, um falso self emerge como uma proteção ao self verdadeiro. $\mathrm{O}$ conceito de self verdadeiro refere-se à potencialidade de sentir-se real e originase na emergência do gesto espontâneo do bebê. No entanto, o self verdadeiro só se tornará uma realidade viva como resultado do êxito contínuo da mãe em resposta à espontaneidade do 
bebê. Somente o self verdadeiro pode ser analisado. Entretanto, o falso self se constrói na base da submissão. Uma mãe não suficientemente boa substitui o gesto espontâneo do bebê por seu próprio gesto, não alimentando, assim, a onipotência do bebê. A submissão ao gesto da mãe dá início ao processo de construção de um falso self. Segundo ele, quando o falso self se vê tratado como real, ocorre um crescente sentimento de futilidade e desespero por parte do indivíduo. Segundo Winnicott (1960/1983), o paciente procura auxílio porque está se sentindo irreal ou fútil, apesar do aparente sucesso da defesa.

As inúmeras cisões características destas formas de constituição subjetiva (como o falso self, os estados esquizoides e a área da falha básica) possuem repercussões nas modalidades de relação de objeto e nos processos de simbolização destes indivíduos. Geram singulares estilos de comunicação presentes de forma maciça na clínica dos casos-limite. Os casos-limite reeditam na relação analítica um passado presentificado, ou seja, mais do que recordar, necessitam repetir estas experiências no âmbito da relação transferencial com o analista.

Torna-se fundamental, portanto, não apenas nos primórdios da vida psíquica como na relação analítica com estes pacientes, o encontro com um interlocutor capaz de conter, metabolizar e transformar em símbolos, sonhos ou narrativas os sentimentos e sensações não simbolizados (Bion, 1963/1994). Assim, para além das interpretações que buscam revelar material inconsciente da posição de intérprete neutro daquilo que se passa com o paciente, a clínica dos casos-limite convoca o analista a uma valorização da qualidade da interação terapêutica e a um intenso trabalho no âmbito da contratransferência.

\title{
Da identificação projetiva à rêverie: de volta ao paradoxo primordial
}

\begin{abstract}
Debussy acreditava que a música era o espaço entre as notas. Pode-se dizer algo similar da psicanálise. Entre as notas das palavras ditas, que constituem o diálogo analítico, estão as reveries do analista e do analisando. Nesse espaço ocupado pelo interjogo de reveries é que se encontra a música da psicanálise. (T. Ogden, 2015, p. 103)
\end{abstract}

Os casos-limite convocam a disponibilidade emocional do analista através do interjogo entre ausência e presença, e de estar ao mesmo tempo junto e separado na relação transferencial. O fenômeno da identificação projetiva, desenvolvido originalmente por Melanie Klein (1946/1991a), consiste tanto em uma forma arcaica de comunicação, quanto em um mecanismo de defesa privilegiado pelo ego incipiente para lidar com estímulos internos e externos. Este conceito é ampliado posteriormente como importante forma de comunicação por Bion (citado por Grinberg, Sor \& Bianchedi, 1973), em sua teoria do pensar, a partir das noções de função alfa e rêverie materna, construídas a partir de sua clínica com pacientes psicóticos e borderlines. A partir de sua obra, o conceito de identificação projetiva emerge como importante ferramenta clínica em uma perspectiva na qual a relação objetal é o vértice primordial de compreensão dos processos de subjetivação.

Melanie Klein (1946/1991a), ao discutir alguns mecanismos específicos dos estados esquizoides, conceitua os processos de idealização, projeção e cisão; e inaugura o termo "identificação projetiva". Sob esta denominação, ela estabelece um mecanismo de defesa, típico da posição esquizoparanoide, no qual uma parte indesejável do self, após a cisão, é projetado para dentro do objeto. Em seus primeiros trabalhos, Klein já sugeria que a primeira defesa do ego diante da ansiedade é a expulsão. Neste início, ela ainda não usava o termo 
projeção, mas a ideia de expulsão violenta do sadismo para aliviar o ego e atacar os objetos persecutórios já estava presente. Outra ideia também considerada precursora do conceito de identificação projetiva era a existência de fantasias arcaicas de intrusão no corpo materno, já presentes em seus trabalhos de 1928 e 1929 (Klein, 1928/1996a; 1929/1996b; 1929/1996c). Klein, citada em Ogden (2015), propõe diferentes formas de subjetivação derivadas de um potencial herdado filogeneticamente, que é ativado no contexto das primeiras relações de objeto. Inaugura, assim, a teoria das posições esquizoparanoide e depressiva que, caracterizadas por diferentes tipos de relações de objeto, ansiedades, fantasias e defesas específicas, oferecem diferentes possibilidades de dar forma e significação às experiências primordiais.

Tal como Fairbairn (1940/1980), Bion também concebe a cisão como mecanismo fundamental da constituição psíquica, considerando a coexistência de núcleos psicóticos e neuróticos como característica universal da personalidade. Foi a partir da obra de Bion que o conceito de identificação projetiva ganhou sua faceta mais radicalmente interpessoal. Este uso ampliado do conceito de identificação projetiva surge no contexto da construção de sua teoria do pensar, na qual Bion (1963/1994) estabelece a existência de pensamentos e de um "aparelho para pensar".

Segundo ele, a atividade do pensar surge para livrar o psiquismo do excesso de estímulos. No termo pensamento, Bion inclui as pré-concepções, as concepções, e os pensamentos propriamente ditos. As pré-concepções são herdadas filogeneticamente, como a préconcepção que o bebê tem do seio materno. As concepções resultam do encontro entre uma pré-concepção e sua experiência de realização. E quando uma pré-concepção não se encontra com a experiência real, ou seja, quando ocorre a combinação de uma pré-concepção e a experiência de frustração, pode surgir, então, o pensamento propriamente dito. Os pensamentos referem-se ao contido.

Com o termo pensar, Bion (1963/1994) designa dois processos diferentes: a relação dinâmica entre o continente (o objeto no qual se projeta) e o contido (aquilo que é projetado); e a relação dinâmica entre a posição esquizoparanoide e depressiva. O êxito ou fracasso da capacidade de rêverie da mãe permite ao bebê introjetar uma dupla continente/contido satisfatória ou fracassada. No entanto, para Bion, o êxito ou fracasso nesta relação depende tanto da forma como a mãe recebe a projeção do bebê (acolhe ou rechaça), como também da (ausência ou presença da) tolerância inata à frustração por parte do bebê.

Anne Alvarez (1994) parte das obras de Freud, Melanie Klein e W. Bion e dialoga com psicólogos do desenvolvimento. Interessa-se por uma das funções maternas que considera primordial, principalmente, em casos cujo sofrimento psíquico remete mais ao isolamento e ao retraimento: a capacidade de a mãe "despertar o interesse" do seu bebê. A partir da afirmação de Trevarthen citada por Alvarez (1994) de que o objeto inanimado, caracterizado pela ausência de movimentos decorrentes de impulsos autogerados, é esta vitalidade rítmica do movimento que primeiro identifica a companhia viva. Alvarez (1994) afirma que estudos a partir da observação de bebês sugerem que alguns bebês buscam contato e vida muito mais ativamente do que outros, mas em todos os recém-nascidos há, desde o início, alguma capacidade para fazer essas distinções entre objetos animados e inanimados. A partir destas pesquisas, Alvarez propõe como função primordial do analista, ao lado da função de rêverie desenvolvida por Bion (1963/1994), a função de revitalização. Ou seja, um esforço consciente feito por parte do analista de resgatar o paciente de estados de isolamento. 
Anne Alvarez (1994) traz ao primeiro plano as noções de perspectiva, proximidade, agarrabilidade e acessibilidade no que concernem a um objeto primário tridimensional. Estas formas que remetem ao objeto primário parecem apontar também para possíveis posições do analista na clínica dos casos-limite. O objeto primordial na forma de espelho aponta para a função analítica especular de refletir a imagem de forma plana, mantendo-se estático e imutável. Aproxima-se à neutralidade do analista indicada por Freud. O objeto tridimensional de Anne Alvarez (1994) indica funções analíticas que se referem à distância, proximidade, agarrabilidade, experiências muito características das atividades exploratórias do bebê (do paciente) no sentido da busca pela relacionabilidade, pela saída do retraimento e por experiências que valem a pena ser exploradas e vividas. Todas estas funções podem ser convocadas pelo paciente em diferentes momentos da relação analítica, não sendo excludentes entre si, mas reveladoras das diferentes dimensões da experiência intersubjetiva que se fazem presentes no setting analítico.

\section{Considerações finais}

Questões centrais para a teoria da técnica analítica, tais como a neutralidade do analista, a interpretação e o manejo da transferência, são postas à prova quando confrontadas com a clínica dos casos-limite. A articulação das ideias, desenvolvidas nos itens anteriores, sugere uma conceituação dos aspectos que definem o "fazer psicanalítico" na dimensão do trauma e dos processos de cisão. Considera-se que uma metapsicologia relacional se torna útil para pensar em novos dispositivos clínicos, novos "fazeres" do analista e em uma constante reflexão sobre a posição que este ocupa na relação transferencial com pacientes intensamente regredidos.

Para auxiliar uma conceituação do fazer psicanalítico no âmbito da falha básica, nos perguntamos: quais são as formas do objeto primário nos diferentes enfoques aqui citados? Melanie Klein, ao enfatizar os processos de introjeção e projeção nas relações precoces, supunha que o bebê absorvia do seio amor e entendimento, tanto quanto o leite e a satisfação sensual. Bion acrescentou a esta metáfora digestiva a função materna responsável por fazer grande parte da digestão mental para o bebê através da sua função de continência e transformação. Anne Alvarez identifica na metáfora digestiva bioniana uma forma côncava do objeto primário. O objeto primordial bioniano sugere uma função analítica de uma "mentecolo". Refere-se à emotividade cuidadosa e ao cuidado emocional, isto é, ao trabalho realizado dentro do analista em relação ao jogo de forças projetivas e introjetivas da dupla paciente-analista.

Winnicott, a partir de uma tradição ferencziana, privilegia a questão da relação de confiança e a possibilidade de o analista exercer sua função de forma "suficientemente boa". $\mathrm{Na}$ teoria da técnica winnicottiana, o elemento clínico privilegiado é o "holding", ou seja, a capacidade do analista de sustentar em sua mente-corpo as emoções do analisando e manterse em uma relação não-intrusiva, permitindo que a experiência de continuidade do ser possa se expandir no paciente. Dentro desta tradição, encontram-se também Fairbairn e M. Balint. Fairbairn (1940/1980) apresenta como uma das principais finalidades de uma análise o afrouxamento dos vínculos com os objetos maus. Balint (1968/1993) propõe a existência de uma regressão terapêutica, positiva ou negativa. Afirma que o fato de a relação transferencial em psicanálise ocorrer em uma relação dual propicia a emergência de aspectos da área da 
falha básica. O que torna a experiência de análise uma oportunidade para a revivência destes aspectos e a possibilidade de sua cicatrização.

A tradição freudo-kleiniana compreende o funcionamento psíquico como emergindo das experiências corporais e de um mundo de sensações. A organização e a significação destas unidades fundamentalmente sensoriais da experiência ocorrem através da função materna composta pelos cuidados físiológicos e engajamento afetivo. W. R. Bion (1963/1994) conceituou como capacidade de rêverie esta função que permite a transformação das experiências sensoriais e emocionais em experiências que possam ser significadas e, portanto, contidas psiquicamente. Gradativamente, o bebê (paciente) poderá introjetar esta função de rêverie e tornar-se autônomo neste processo de metabolização de suas próprias experiências, dispensando a prótese representada por quem exerce a função materna (analista).

Bion mostrou como determinados pacientes necessitam que $o$ analista suporte determinados estados emocionais, alocando nele partes não reconhecidas de seu próprio self e fazendo, assim, com que o analista desempenhe uma função de prótese ou de rêverie materna. Ou seja, o analista irá tolerar, conter, metabolizar e transformar as partes cindidas e projetadas pelo paciente para dentro dele (analista), tal como a mãe que pode conter as crises e excitações de seu bebê, metabolizá-las e transformá-las em experiências suportáveis. No momento apropriado, o analista oferecerá estes elementos, transformados em imagens ou palavras para a compreensão emocional do paciente.

Anne Alvarez (1994) acrescenta, a esta função de rêverie do analista, a função que se define como "tomar para si" a atenção do bebê pela mãe, surpreendê-lo delicadamente, chamá-lo para a interação prazerosa é tão fundamental quanto a função de continente das ansiedades e terrores inomináveis do bebê. Esta última, definida pela metáfora da digestão alimentar, quando sobre a mãe recaem as projeções das partes cindidas do bebê, cabendo a ela contê-las, metabolizá-las e devolvê-las sobre a forma de símbolos ao bebê, foi nomeada por Bion como a capacidade de rêverie materna. No entanto, para Alvarez a capacidade de rêverie que permite o desenvolvimento futuro de uma função alfa, ou seja, a função de pensar seus próprios pensamentos, é tão fundamental na constituição subjetiva quanto a capacidade de o cuidador resgatar o bebê de movimentos de retraimento para ligar-se a ele, na direção de uma busca ativa por parte do cuidador no sentido da relacionabilidade. Esta função de revitalização levada para a relação transferencial pode ser de extrema valia, principalmente nos momentos de retraimento, tão característicos dos chamados casos-limite.

Considerando as repercussões dos traumas precoces para a constituição das subjetividades, torna-se imprescindível direcionar a investigação psicanalítica para um viés cada vez mais intersubjetivo. Neste sentido, parece claro que a marca primordial da relação transferencial/contratransferencial na clínica dos casos-limite remete ao paradoxo da unidade na dualidade. Ou seja, estabelece-se uma relação analítica na qual emergem sentimentos, sensações e pensamentos referentes à dimensão anterior à delimitação das fronteiras psíquicas. E a partir disto, podemos pensar até em subverter a noção de "casos-limite" para relação analítica-limite, onde o que importa para a saída dos impasses seria sempre uma compreensão do que se passa na dupla, nessa nova entidade psicológica formada pelas contribuições do analista e do paciente. 


\section{Referências}

Alvarez, A. (1994). A companhia viva: psicoterapia psicanalítica com crianças autistas, borderline, carentes e maltratadas. (M. A. V. Veronese, trad.). Porto Alegre, RS: Artes Médicas Sul.

Balint, M. (1993). A falha básica. In M, Balint, Aspectos terapêuticos da regressão (pp. 16-20-). Porto Alegre, RS: Artes Médicas. (Trabalho original publicado em 1968)

Bick, E. (1991). A experiência da pele em relações de objeto arcaicas. In E. B. Spillius, Desenvolvimento da teoria e da técnica (pp. 194-198). Rio de Janeiro, RJ: Imago. (Trabalho original publicado em 1967)

Bion, W. R. (1994). Estudos psicanalíticos revisados (W. M. de M. Dantas, trad., 3a ed.). Rio de Janeiro, RJ: Imago. (Trabalho original publicado em 1963)

Cardoso, M. R. (2006). A insistência do traumático no espaço psíquico e psicanalítico. Pulsional: Revista de Psicanálise, 19(185), 7-19. Recuperado de http://www.fundamentalpsychopathology.org.br/uploads/files/encontro_cientifico_2005/ec_marta_rezende_cardoso.pdf

Fairbairn, W. R. (1980). Estudos psicanalíticos da personalidade (E. Nick, trad.). Rio de Janeiro, RJ: Interamericana. (Trabalho original publicado em 1940)

Figueiredo, L. C. (1999). O caso-limite e as sabotagens do prazer. Revista Latinoamericana de Psicopatologia Fundamental, 3(2), 61-87. Recuperado de http://www.scielo.br/pdf/rlpf/v3n2/14154714-rlpf-3-2-0061.pdf

Freud, S. (1996). Formulações sobre os dois princípios de funcionamento mental. In S. Freud, Edição standard brasileira das obras completas de Sigmund Freud (J. Salomão, trad., Vol. 12, pp. 277286). Rio de Janeiro, RJ: Imago. (Trabalho original publicado em 1911)

Freud, S. (1996). O Ego e o Id. In S. Freud, Edição standard brasileira das obras completas de Sigmund Freud (J. Salomão, trad., Vol. 19, pp. 23-83). Rio de Janeiro, RJ: Imago. (Trabalho original publicado em 1923)

Garcia, C. A. (2007). Os estados limite e o trabalho do negativo: uma contribuição de A. Green para a clínica contemporânea. Revista Mal-Estar e Subjetividade, 7(1), 123-135. Recuperado de http://pepsic.bvsalud.org/scielo.php?script=sci_arttext\&pid=S1518-61482007000100008

Grinberg, L., Sor, D., \& Bianchedi, E. (1973). Introdução às idéias de Bion (T. de O. Brito, trad.). Rio de Janeiro, RJ: Imago.

Joseph, B. (1992). O paciente de difícil acesso. In M. Feldman, \& E. B. Spillius (Eds.), Equilíbrio psíquico e mudança psíquica (pp. 85-96). Rio de Janeiro, RJ: Imago. (Trabalho original publicado em 1975)

Kernberg, O. (1979). Borderline conditions and pathological narcisism (6a ed.). New York: Jason Aronson.

Klein, M. (1991a). Notas sobre alguns mecanismos esquizoides. In M. Klein, Inveja e gratidão e outros trabalhos (1946-1963) (pp. 17-43). Rio de Janeiro, RJ: Imago. (Trabalho original publicado em 1946)

Klein, M. (1991b). As origens da transferência. In M. Klein, Inveja e gratidão e outros trabalhos (1946-1963) (pp. 70-79). Rio de Janeiro, RJ: Imago. (Trabalho original publicado em 1952)

Klein, M. (1996a). Estágios iniciais do conflito edipiano. In Amor, culpa e reparação e outros trabalhos. (pp. 214-227). Rio de Janeiro: Imago Ed., 1996. (Trabalho original publicado em 1928a)

Klein, M. (1996b). Personificação no brincar das crianças. In Amor, culpa e reparação e outros trabalhos. (pp. 228-239). Rio de Janeiro: Imago Ed., 1996. (Trabalho original publicado em 1929) 
Klein, M. (1996c). Situações de ansiedade infantil refletidas em uma obra de arte e no impulso criativo. In Amor, culpa e reparação e outros trabalhos. (pp. 240-248). Rio de Janeiro: Imago Ed., 1996. (Trabalho original publicado em 1929)

Ogden, T. H. (1994). The concept of internal object relations. In J. S. Grotstein, \& D. B. Rinsley (Orgs.), Fairbairn and the origins of object relations (pp. 88-112). London: Free Association Books.

Ogden, T. H. (1996). Os sujeitos da psicanálise. São Paulo, SP: Casa do Psicólogo.

Ogden, T. H. (1997). Reverie and interpretation: sensing something human. London: Jason Aronson Inc.

Ogden, T. H. (2015). A matriz da mente: relações objetais e o diálogo psicanalítico (G. D. G. da Silva, trad.). São Paulo, SP: Karnac.

Peixoto Junior, C. A. (2011). Os limites da representação na experiência esquizoide. In: C. A. Garcia, \& M. R. Cardoso (Orgs.), Limites da clínica: clínica dos limites (pp. 93-102). Rio de Janeiro, RJ: Cia de Freud.

Peixoto Junior, C. A. (2013). Michael Balint: a originalidade de uma trajetória psicanalítica. Rio de Janeiro, RJ: Revinter.

Steiner, J. (1994). O equilíbrio entre as posições esquizo-paranoide e depressiva. In R. Anderson (Org.), Conferências clínicas sobre Klein e Bion (B. Mandelbaum, trad., pp. 60-72). Rio de Janeiro, RJ: Imago. (Trabalho original publicado em 1992)

Tustin, F. (1990). O desenvolvimento do "Eu". In F. Tustin, Barreiras autistas em pacientes neuróticos (pp. 174-190). Porto Alegre, RS: Artes Médicas.

Winnicott, D. W. (1983). Da dependência à independência no desenvolvimento do indivíduo. In D. W. Winnicott, $O$ ambiente e os processos de maturação: estudos sobre a teoria do desenvolvimento emocional (I. C. S. Ortiz, trad., pp. 79-87). Porto Alegre, RS: Artes Médicas. (Trabalho original publicado em 1963)

Winnicott, D. W. (1983). Distorção do ego em termos de falso e verdadeiro self. In D. W. Winnicott, O ambiente e os processos de maturação: estudos sobre a teoria do desenvolvimento emocional (I. C. S. Ortiz, trad., pp. 128-139). Porto Alegre, RS: Artes Médicas. (Trabalho original publicado em 1960)

Winnicott, D. W. (2000). Objetos transicionais e fenômenos transicionais. In D. W. Winnicott, Da pediatria à psicanálise: obras escolhidas (D. Bogomoletz, trad.). Rio de Janeiro, RJ: Imago. (Trabalho original publicado em 1951)

Recebido em maio/2018 - Aceito em fevereiro/2019. 